\title{
Establishing a Soldier Wireless Sensor Network (WSN) Communication for Military Operation Monitoring
}

\author{
Mohd Nazri Ismail', Mohd 'Afizi Shukran, Mohd Rizal Mohd Isa, Mohd Adib, Omar Zakaria \\ Faculty of Defense Science and Technology, National Defence University of Malaysia (UPNM), Sungai Besi, \\ Kuala Lumpur, Malaysia
}

\begin{tabular}{l} 
Article Info \\
\hline Article history: \\
Received Apr 13, 2018 \\
Revised Jun 15, 2018 \\
Accepted Jun 29, 2018 \\
\hline
\end{tabular}

\section{Keywords:}

Health

Knowledge

Military

Mobile

Prototype

Wireless sensor network (WSN)

\begin{abstract}
The study investigates and develops components for implementing an effective and efficient military knowledge/information/communication in closed network architecture. Since military personnel are always on the move, the dissemination of knowledge/information/communication needs a mobile platform to accommodate mobility of people. The mobile and wireless network platform should be able to sustain the remoteness and seclusion of military operation areas. Communication is one of key problems of a military operation especially due to environmental constraints. This study proposes on establishing a future soldier communication device with mobile Wireless Sensor Network (WSN) and mobile network to suit the infantry operations in the jungle. The operational areas are considered to restricted and challenging locations. Wireless Sensor Network (WSN) will become inexpensive and common over the next decade Thus, a thorough study is vital to develop the most suitable smart equipment and network requirements for Malaysia's military eco-system. Finally, this study has successfully developed new smart device prototype using WSN approach for Military operation. In addition, this prototype can be used for Search and Rescue (SAR) operation. This prototype is able to transmit death and location status, movement location status, health monitoring and status to the base station.
\end{abstract}

Copyright () 2018 Institute of Advanced Engineering and Science. All rights reserved.

\section{Corresponding Author: \\ Mohd Nazri Ismail, \\ Faculty of Defense Science and Technology, \\ National Defence University of Malaysia (UPNM), \\ Sungai Besi, Kuala Lumpur, Malaysia. \\ Email: m.nazri@upnm.edu.my}

\section{INTRODUCTION}

Cutting edge computer network technologies facilitates sharing knowledge and information among personnel in many organizations. Knowledge and Information must now be treated as a critical resource to the organization in addition to land and raw materials. In military, initiatives labeled as Knowledge Management $(\mathrm{KM})$, the focus is on learning and the sharing of tacit knowledge, particularly in the many areas of military operations [1,2]. Since military personnel are always on the move, the dissemination of knowledge and information needs a mobile platform to accommodate mobility of people. The mobile and wireless network platform should be able to sustain the remoteness and seclusion of military operation areas.

Future soldier is a concept of how the future Soldier might be equipped. The future Soldier shall be tailored with design considerations for each technology area name below with special emphasis on cognitive performance to improve Soldier effectiveness and an increase in operational tempo. There are seven major areas within Future Soldier [3]: i) Human Performance \& Training, ii) Soldier Protection; iii) Lethality; iv) Mobility and Logistics, v) Soldier_Network; vi) Soldier_Sensors; vii) Soldier Power \& Energy. The smart device using Wireless Sensor Network (WSN) is developed based on four areas i) Lethality, ii) Mobility, iii) Soldier 
Network, and iv) Soldier Sensors. This approach is not focusing on military information but it is also can be applied to SAR (Search and Rescue) team unit.

Communication is one of key problems of a military operation especially i) there is no death notification status mechanism, ii) unable to track the movement and location of soldier in real time, iii) unable to monitor injured soldier from base station. Hence, this study proposes on establishing a future soldier communication device embedded with wireless sensor network to suit the military operations in the jungle. Thus, a thorough study is vital to develop the suitable equipment and network requirements for Malaysia's military eco-system. Thus, the objectives of this research are as follows:

i. Develop and execute processes that engage current soldiers and partners in the identification and analysis of future Soldier.

ii. Create future operations and support future capability identification and analysis.

iii. Innovators in the research community to better understand how future science and technology can enable future Soldier

iv. To develop a smart device communication (IoT) using radio frequency (RF) network and mobile network for military HQ remote monitoring.

The rest of the paper is organized as follows: background and related work is presented in Section 2, while Section 3 discusses on methodology. This is followed by Section 4 with a design and result of smart device using wireless sensor network approach. Finally, in Section 5, the paper is concluded with a brief summary and future research work.

\section{BACKGROUND AND RELATED WORK}

Infantry have always been inspired to the ideal of 'one shot, one kill' in the military training, but this article proves that, especially in complex terrains such as the jungle area, infantry usually applies the "volume of fire' psychological approach to dominate their enemy. Only then the significant challenges of poor visibility and fleeting engagement opportunities are successfully overcome and maneuver restored to the light infantryman [4].

Communication is the key aspect in military operations [5]. Throughout the ages, man have used many different modes of communication. Be it as pictography, sign languages, lights, smokes and many other symbolic ways in such that some even encrypted to hide the actual data that is being relayed. With the creativity of man to come up with many different ways of communicating, come challenges of making it much more effective. But in terms of military operations, communications have to be brief, precise and relayed to the target at pin point accuracy. The common mode of communicating has always been through voice radio. Soldiers of the world are much more dependent on current electronic warfare technology to win the war. These new emerging technology comes with a price, other than the value of money, the sum is weight is a major factor. Compared to soldiers of the first world war, soldiers of today have to carry almost double the weight. There are other methods being used in the history of military communication other than radio waves which are mainly in electronic signals and optical signals. Examples for electronic signals are telephone where the telephone converts the voice into electronic signal through the circuits in the telephone. Whereas for optical signals, it will receive the converted signals in a form of lights to be transmitted into the fibre optic cable that will then will be converted into electronic signals that will be convert into data via electronic devices, such as computers [6].

A mesh network is a perfect fit for military operations because it is wireless and mobile rather than the traditional hub-and-spoke networking model which requires a physical connectivity and a centralized router. Instead, mesh networks transmits a relay system that lets each node act independently to receive and disseminate information and then forward them to the other nodes. It does not only works with the forwardoperating units to collects data such as visual and sound on the surroundings of the required area that does not facilitate with the networking infrastructure, but it can also be configured accordingly with a much more efficient and quickly and considered as a much more reliable because it can bypass nodes that are operating sub optimally automatically in favor of the much more quickest and most robust pathway. Example of organization that has been using the mesh network is the United States Marines [7].

Based on the reviews, we can deduce that it is feasible to establish a wireless sensor network for infantry personnel during military operations $[8,9,10,11]$. The following sections describes further on the research issues, objectives and the proposed network structure. 


\section{THE PROPOSED WIRELESS SENSOR NETWORK STRUCTURE}

The approach of this research will be conducted according to the objectives that have been stated as above. Initial study would be concentrated in understanding the mechanics and characteristics of a wireless sensor network and wireless mesh network. A handful of papers related to the research and development of the wireless network will be studied $[12,13,14]$. A wireless sensor network is a group of network which usually uses wireless or cabled network where each of the devices is connected from one to many. It needs to be configured to allow connections to be rerouted by avoiding obstacle objects that may be block the signals from being transmitted by hoping the nodes from one device to another until it reaches its destination. Wireless sensor networks are self-healing and very reliable $[15,16,17]$. Figure 1 illustrates the proposed framework of wireless sensor network structure for infantry operations [17, 18].

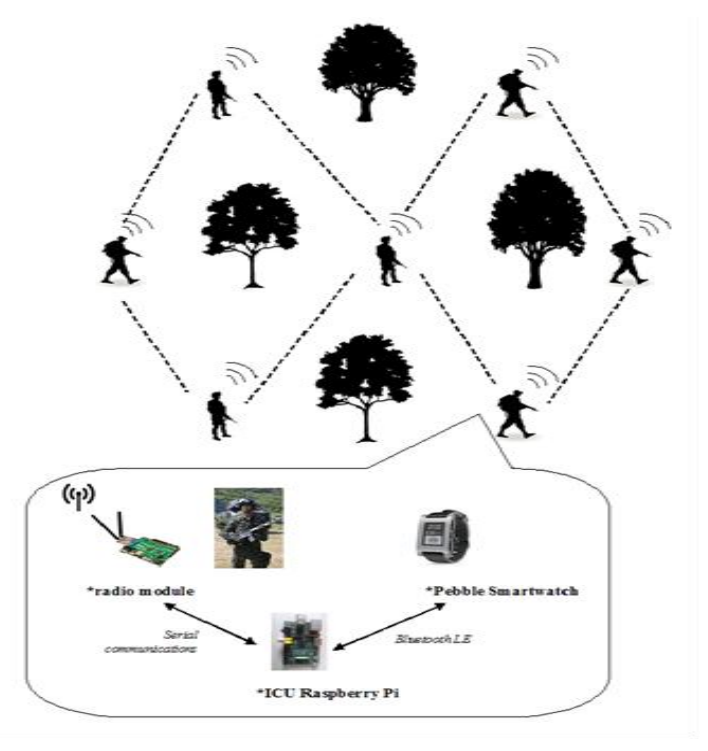

Figure 1. Framework of Wireless Sensor Network for Military Unit

\section{RESEARCH METHODOLOGY}

The following methods would be applied to complete the project objectives (refer to Figure 2):

a. Abstraction Modelling: In the first step, it is required to design the smart device system which has a communication component. The layout of smart device system with its components is designed on the drawing paper (Abstraction Modelling)

b. Block Diagram Design: Next, from abstraction modelling the smart device communication will transform to the Block diagram design. In this stage, the communication components need to arrange and link each other's. The Radio frequency (RF) sensor, GPS sensor, temperature \& humidity sensor, 6DOF sensor and Controller unit are used as communication unit.

c. Device Architecture: The next step, the block diagram design would be to transform into device architecture. The smart device will then be integrated with activation programming communication system. The smart device prototype will be tested and the best performance will be used on smart device communication for military/SAR unit team.

d. Real Smart Device Communication: In the final stage of the project, it is expected to have a successful communication on real network between smart device, wireless gateway and HQ base station. It helps to enhance the driving experience to be safer by having an effective communication between them. After that, the performance will be test and analyse in real operation monitoring and tracking situation. 


\section{STEP 1}

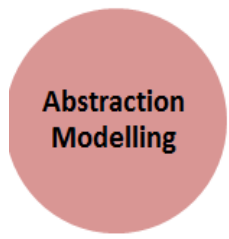

STEP 2

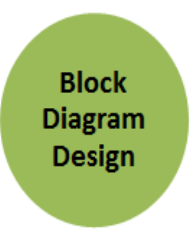

STEP 3

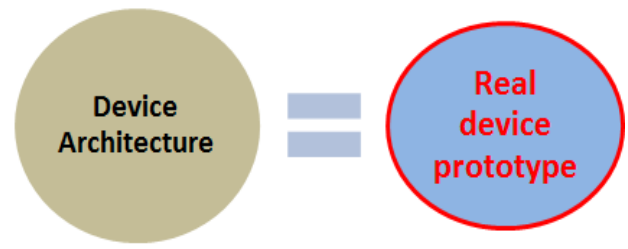

Figure 2. Research Methodology

\section{DESIGN AND RESULT}

\subsection{Abstraction Model- Soldier Unit}

In the first phase, the overview of the smart device unit using wireless sensor network has been sketch properly has been sketch properly. Figure 3 shows the illustration layout of smart device embedded with wireless sensor network.

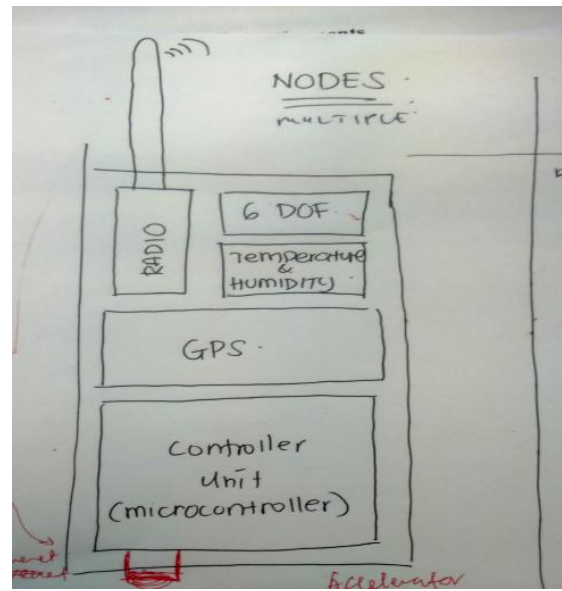

Figure 3. Illustration of Smart Device Wireless Sensor Network

\subsection{Block Diagram Design of Wireless Sensor Network}

The second phases, all the sensor components have been assembled and connected to block diagram design (Refer to Figure 4). There are six components have been used in development of smart device WSN for military operation such as: GPS sensor, Radio Sensor (RF), Temperature sensor, humidity sensor, 6DOF sensor. Five of these sensors have connected/linked to the Micro Controller Unit.

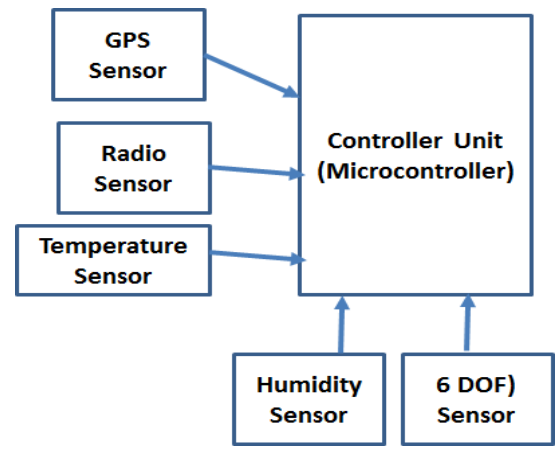

Figure 4. Smart Devices WSN - Block Diagram Design for Military Unit 


\subsection{Device Architecture Layout} 5.3.1 GPS Sensors

The GPS sensor is used for soldier position tracking and health indication status monitored from base station (refer to Figure 5). The GPS receiver is used to log the longitude and latitude of military team unit, which is stored in microcontroller memory. GPS Receiver receives and compares the signal from orbiting GPS satellite to determine geographic position.

\subsubsection{DoF Sensor}

Six degrees of freedom (6DoF) refers to the freedom of movement of a rigid body in three-dimensional space. Specifically, the body is free to change position as forward/backward (surge), up/down (heave), left/right (sway) translation in three perpendicular axes, combined with changes in orientation through rotation about three perpendicular axes, often termed pitch, yaw, and roll [19]. In this research 6DoF is used to detect the death status of the military (refer to Figure 5).

\subsubsection{Temperature and Humidity Sensor}

This temperature and humidity is used for health monitoring and death status. The humidity sensor is used to measure the surrounding air. This temperature sensor is used to measure the military body temperature (refer to Figure 5).

\subsubsection{Radio Frequency (RF) Sensor}

This RF sensor is used for communication between military team to Mobile Ad-Hoc Network (MANET) gateway, then Mobile Ad-Hoc Network (MANET) gateway will be linked to the Base station (HQ) for real time monitoring (refer to Figure 5).

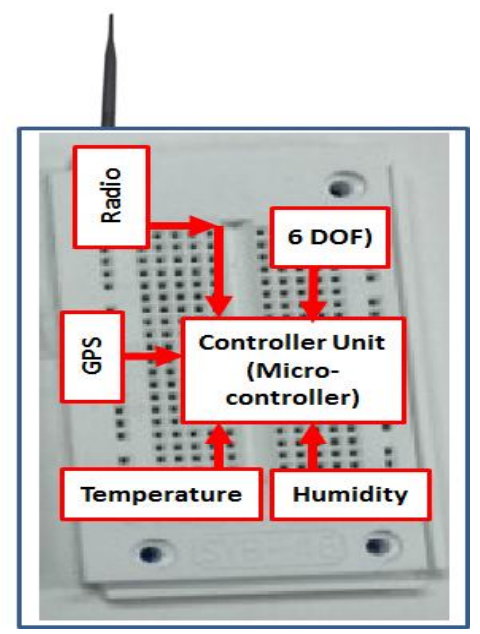

Figure 5. Device Architecture Layout

\subsection{Real Smart Device WSN Prototype}

At the end of the research, we are finally successfully developed Real Smart Device Prototype using Wireless Sensor Network (WSN) approach. Figure 6 shows the top view and side view of real smart device prototype. Table 1 show the specification of the Radio Frequency (RF) [20] used in smart device development.

Table 1: Specification, Feature and Support

\begin{tabular}{ll}
\hline \multicolumn{1}{c}{ Specification/feature } & \multicolumn{1}{c}{ Support } \\
\hline Radio Frequency (RF) bands & $433 \mathrm{MHz}, 868 \mathrm{MHz}$ \\
Output power & $+14 \mathrm{dBm}$ (max.), adjustable \\
Modulation & FSK, GFSK, Lora supported modulation \\
receiver sensitivity & supports till $-148 \mathrm{dBm}$ \\
distance coverage & $>15 \mathrm{Km}$ (sub-urban), >5Km (urban) \\
Applications & IoT, M2M etc. \\
Supply Voltage & $2.1 \mathrm{~V}$ to 3.6 Volts \\
Temperature range & -40 degree $\mathrm{C}$ to +85 degree C \\
\hline
\end{tabular}



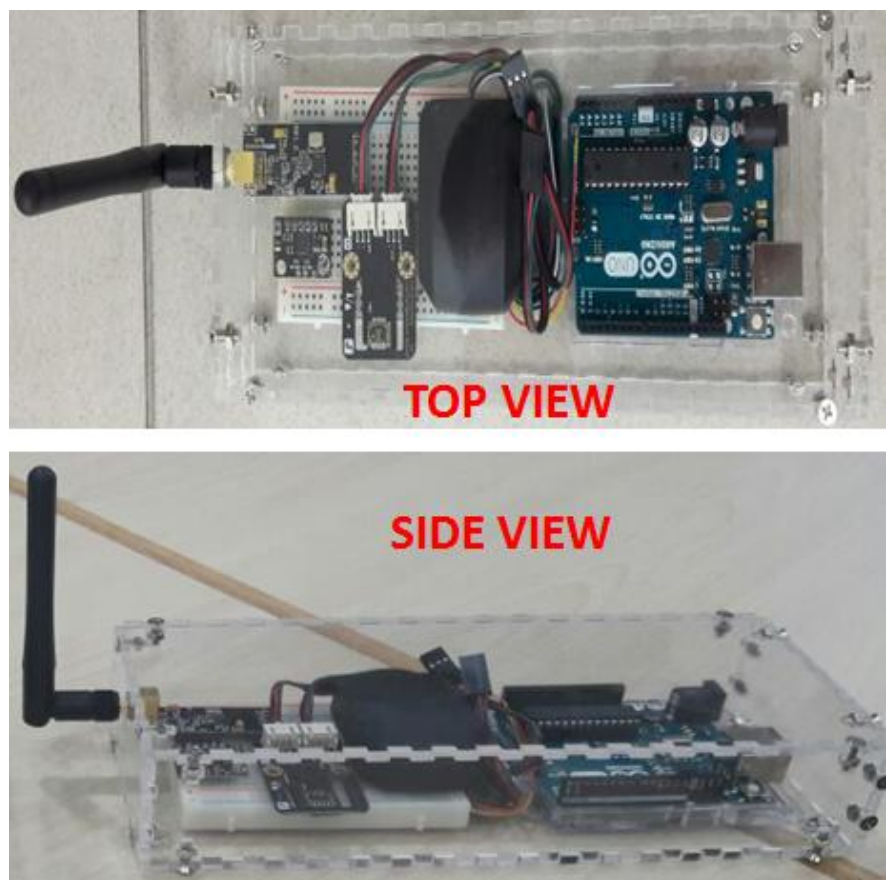

Figure 6. Real Smart Device Prototype using WSN Approach

\section{SIGNIFICANT CONTRIBUTION AND FUTURE WORKS}

Finally, this study has successfully developed new smart device prototype using Wireless Sensor Network (WSN) approach for Military operation. In addition, this prototype can be used for Search and Rescue (SAR) operation. This prototype is able to transmit death and location status, movement location status, health monitoring and status to the base station. In general, the contribution of this research would benefit the university and the military. At the university level, a broad field of study could emerge from this research.

The further enhancement of the wearable eco system that consists of a smart glass/goggles and also smart clothing could be included into the eco system. With a smart glass, a heads up display could be provided to the user thus saving precious time and could be coupled with augmented reality for further enhancement of situational awareness. By having heads up display, mad and field can be integrated into augmented reality. Clothes that collects physical parameters such as heart rate and perspiration rate would mean a whole new level on the term of smart soldiers. Base situation could monitor infantry physical and mental condition, stress level and provide the appropriate remedy or re-group if retreat is imminent.

Also, next future work needs to be focused on consumption of power energy and distance. The architecture of this smart device can further extend to add display unit and motion detection

\section{ACKNOWLEDGEMENTS}

This research and funding was supported by KPT (Ministry of Higher Education). The area of study is on military using NRGS grant.

\section{REFERENCES}

[1] W. Wong, "Military Battlefiled IT. FEDTECH". (2012) http://www.fedtechmagazine.com/article/2012/08/howmesh-networks-extend-military-comm

[2] Puteri NE Nohuddin, M. Isa, M. Rizal, M.A. Mohd Shukran, "Information Technology Knowledge Management in Malaysian Armed Forces”. Journal of Convergence Information Technology 7 vol. (6) (2012)

[3] G.G Casey, “Future Soldier”,2009, https://www.wired.com/images_blogs/dangerroom/2009/05/dplus2009_ 11641-1.pdf

[4] Dr B. Hall, Dr A. Ross, "Bang on target? Infantry marksmanship and combat effectiveness in Vietnam", (2009)

[5] Maseng, T. et all., "Military Communications", 2013 http://ieeexplore.ieee.org/xpls/abs_all.jsp?arnumber=6619562

[6] J. Hecht, "Understanding Fiber Optics", Fifth Edition Revised, 2015 
[7] A. Weintrit, "Marine Navigation and Safety of Sea Transportation", 2009.

[8] Kassim, M., C.K.H.C.K. Yahaya and Mohd.Nazri Ismail, 2010. "A prototype of web based temperature monitoring system". Proceedings of the IEEE, International Conference on Information and Network Technology, June 22-24, 2010, Shanghai, China, pp: 266-270.

[9] Kassim, M., C.K.H.C.K. Yahaya and Mohd.Nazri Ismail, 2010. "A study on automated, speech and remote temperature monitoring for modeling web based temperature monitoring system". Proceedings of the IEEE, International Conference on Information and Network Technology, June 22-24, 2010, Shanghai, China, pp: 229-233.

[10] M. T. Ismail, M. N Ismail, S. S. Sameon, Z. M. Zin, N. Mohd, 'Wireless Sensor Network: Smart greenhouse prototype with smart design', 2016 2nd International Symposium on Agent, Multi-Agent Systems and Robotics (ISAMSR), 2016, pp. 57-62. doi: 10.1109/ISAMSR.2016.7810003

[11] M. N. Ismail. "Early fire detection: development of temperature sensor device in smart home monitoring system using mobile phone". International Journal of Academic Research (IJAR), Part A; 4(5), 41-49, 2012

[12] Raniwala, A., Tzi-cker C., "Architecture and algorithms for an IEEE 802.11-based multi-channel wireless mesh network".http://ieeexplore.iee.org/xpl/abstractAuthors.jsp?tp=\&arnumber=1498497\&url=http\%3A\%2F\%2Fieeex plore.iee.org\%2Fxpls\%2Fabs_all.jsp\%3Farnumber\%3D1498497

[13] Aguayo, D et all., "Link-level measurements from an 802.11b mesh network", 2004.

[14] Bicket. J et all., "Architecture and evaluation of an unplanned 802.11b mesh network", 2005.

[15] Karrer, R et all., "Challenges in Second-Generation Wireless Mesh Networks", 2008. http://www.jwcn.eurasipjournals.com/content/2008/1/274790\#sec5

[16] Russel, K., "Mesh Networks", 2009. http://www.computerworld.com/article/2550305/mobile-wireless/meshnetworks.html

[17] A.K.A. Ghani, M.N. Ismail, Z. Omar, Puteri N. E. Nohuddin, "Establishing mesh network amongst infantry personnel during military operations: A preliminary study". 2016 International Conference on Information and Communication Technology (ICICTM), IEEE 16th - 17th May 2016, Kuala Lumpur, Malaysia.

[18] Nancy J. Wesenten, Gregory Belenky, Thomas J, Balkin, "Cognitive Readiness in Network-Centric Operations", Parameters, Spring 2005, pp, 94-105.

[19] Six Degrees of Freedom, https://en.wikipedia.org/wiki/Six_degrees_of_freedom

[20] LoRa Alliance, "A technical overview of LoRa and LoRaWAN", https://www.lora alliance.org/portals/0/documents/whitepapers/LoRaWAN101.pdf, 6 June 2017 